Check for updates

Cite this: RSC Adv., 2018, 8, 1987

\title{
Enhancement of $\mathrm{CO}_{2}$ capture performance of aqueous MEA by mixing with $\left[\mathrm{NH}_{2} \mathrm{e}-\mathrm{mim}\right]\left[\mathrm{BF}_{4}\right]$
}

\begin{abstract}
Mei Wang, (D)* Mingming Wang, Na Rao, Jiale Li and Jianfen Li*
Alcohol amine solutions have a high absorption capacity and rate for $\mathrm{CO}_{2}$ capture, however, there are some shortcomings such as high energy-consumption and low stability. To enhance $\mathrm{CO}_{2}$ capture performance of aqueous MEA, a functional ionic liquid ( $\left.\left[\mathrm{NH}_{2} \mathrm{e}-\mathrm{mim}\right]\left[\mathrm{BF}_{4}\right]\right)$ was introduced based on the advantages for $\mathrm{CO}_{2}$ capture. Absorbents were prepared with the molar concentration ratio of $\left[\mathrm{NH}_{2} \mathrm{e}-\mathrm{mim}\right]\left[\mathrm{BF}_{4}\right]$ to the 30 vol\% aqueous MEA of $0: 10,1: 9,2: 8,3: 7,4: 6$ and $6: 4$. The density and the viscosity of the investigated absorbents were measured and the effects of the molar fraction of $\left[\mathrm{NH}_{2} \mathrm{e}-\mathrm{mim}\right]\left[\mathrm{BF} \mathrm{F}_{4}\right]\left(n_{1}\right)$ and temperature on $\mathrm{CO}_{2}$ absorption performance were investigated. $\mathrm{CO}_{2}$ desorption performance of the solvent at different temperatures was discussed. The stability performance of the absorbent with $n_{1}$ of $2: 8\left(\mathrm{I} / \mathrm{M}_{2: 8}\right)$ was examined by five consecutive cyclic tests. The results showed that for pure $\mathrm{CO}_{2}$, the $\mathrm{I} / \mathrm{M}_{2: 8}$ displayed the highest absorption performance at $303 \mathrm{~K}$ under 1 bar: a comparable $\mathrm{CO}_{2}$ absorption capacity of the 30 vol\% aqueous MEA and a higher $\mathrm{CO}_{2}$ absorption rate at the later absorption stage. Moreover, with the increase of temperature, $\mathrm{CO}_{2}$ absorption capacity and rate decreased, while $\mathrm{CO}_{2}$ desorption efficiency and rate increased. $393 \mathrm{~K}$ was chosen as the optimum desorption temperature with the desorption efficiency of $99.31 \%$. The introducing of $\mathrm{IL}$ contributed to $\mathrm{CO}_{2}$ desorption performance of the absorbents significantly. The properties $\left(\mathrm{CO}_{2}\right.$ absorption capacity, mass loss, density and viscosity) of the $\mathrm{I} / \mathrm{M}_{2: 8}$ during the cycles suggested that the IL-MEA mixture had an excellent stability performance.
\end{abstract}

Received 25th October 2017 Accepted 12th December 2017 DOI: $10.1039 / c 7 r a 11757 d$

rsc.li/rsc-advances considering their high $\mathrm{CO}_{2}$ capture performance and reutilization. ${ }^{15-19}$ Among these, functionalized ILs, which could simultaneously improve absorption rate and selectivity of $\mathrm{CO}_{2}$ capture through the reversible reactions between reactive group of the ILs and $\mathrm{CO}_{2}$, have been intensively investigated in the past several decades. ${ }^{1,20-22}$ Bates et al. synthesized the IL (1-(1aminopropyl)-3-butylimidazole fluoroborate, $\left[\mathrm{NH}_{2} \mathrm{p}\right.$-bim $\left.]\left[\mathrm{BF}_{4}\right]\right)$ with amine moieties as the functional groups. ${ }^{23}$ The IL shows a high adsorption capacity of $0.5 \mathrm{~mol} \mathrm{CO}_{2}$ per mol IL. In addition, some other studies also found that the aminefunctionalized ILs have high $\mathrm{CO}_{2}$ capture performance. ${ }^{24-27}$ However, the high viscosity of this amine-functionalized ILs influenced the mass transfer between the liquids and the gas seriously, resulting in a low $\mathrm{CO}_{2}$ absorption capacity. ${ }^{28-32}$

In this paper, a new kind of solvent was developed by mixing an amine-functionalized IL (1-(1-aminoethyl)-3-methylimidazole fluoroborate $\left.\left[\mathrm{NH}_{2} \mathrm{e}-\mathrm{mim}\right]\left[\mathrm{BF}_{4}\right]\right)$, with $30 \mathrm{vol} \%$ aqueous MEA solutions to investigate whether there was a synergetic effect on $\mathrm{CO}_{2}$ capture performance. The effects of the molar concentration ratio of $\left[\mathrm{NH}_{2} \mathrm{e}-\mathrm{mim}\right]\left[\mathrm{BF}_{4}\right]$ to $\mathrm{MEA}$ in the mixture and the temperature on $\mathrm{CO}_{2}$ absorption performance of the solvents were explored. Further, the desorption performance of the solvents at different temperature were discussed. Moreover, the cyclic stability of the absorbents were evaluated by five consecutive $\mathrm{CO}_{2}$ absorption-desorption tests.
School of Chemical and Environmental Engineering, Wuhan Polytechnic University, Wuhan, Hubei 430023, PR China. E-mail: wangmei0223@hotmail.com; lijfen@163. com; Tel: +862783963954 


\section{Experimental}

\section{Materials}

$\mathrm{CO}_{2}$ (purity $\geq 99.99 \%$ ) was purchased from Wuhan Minghui gas Co., Ltd., China. Ethanolamine (MEA, AR) and sodium borate $\left(\mathrm{NaBF}_{4}, \mathrm{CP}\right)$ were purchased from Sinopharm Chemical Reagent Co., Ltd., China. 2-Bromine ethylamine hydrobromide $\left(\mathrm{C}_{2} \mathrm{H}_{7} \mathrm{Br}_{2} \mathrm{~N}, 98 \%\right)$ and 1-methylimidazole $\left(\mathrm{C}_{4} \mathrm{H}_{6} \mathrm{~N}_{2}, 99 \%\right)$ were provided by Aladdin Reagent Co., Ltd., China.

\section{Characterization and measurement}

Preparation of the investigated solvents. $\left[\mathrm{NH}_{2} \mathrm{e}-\mathrm{mim}\right]\left[\mathrm{BF}_{4}\right]$ was synthesized and the purity was measured according to our previous work..$^{22,33,34}$

An appropriate amount of material was taken in a closed flask according to the molar concentration ratio of the $\left[\mathrm{NH}_{2} \mathrm{e}\right.$ $\operatorname{mim}]\left[\mathrm{BF}_{4}\right]$ to the 30 vol\% aqueous MEA of $0: 10,1: 9,2: 8$, $3: 7,4: 6$ and $6: 4$. The corresponding molar fraction of $\left[\mathrm{NH}_{2} \mathrm{e}-\right.$ $\operatorname{mim}]\left[\mathrm{BF}_{4}\right]\left(n_{\mathrm{I}}\right)$ was $0,0.1,0.2,0.3,0.4,0.6$. It was mixed evenly by ultrasonic vibration.

Measurement of physical properties. The density was measured using a density meter (DM45 Delta Range, Mettler Toledo of Switzerland) that operated via electromagnetically induced oscillation of a glass U-form tube, with automatic compensation for variations in atmospheric pressure. The accuracy of the density meter measurements was $\pm 0.00005 \mathrm{~g} \mathrm{~cm}^{-3}$ for all operating conditions.

The viscosity was measured using a viscometer (DV-II+ Pro, Brookfield of USA). The "ULA" spindle and jacketed sample cell were used for these relatively low viscosity absorbents. The accuracy of viscometer was $\pm 1 \%$ of the reading for torque measurement with a repeatability of $\pm 0.2 \%$ of the reading. The temperature of the jacketed sample chamber was controlled via a circulating bath (TC-602P, Brookfield of USA) with a temperature stability of $\pm 0.01 \mathrm{~K}$.

The mass of the solution was measured by a precision electronic balance (AR2140, Mettler Toledo of Switzerland). The accuracy of the mass measurements was $\pm 0.00001 \mathrm{~g}$.

Determination of $\mathrm{CO}_{2}$ absorption/desorption performance. $\mathrm{CO}_{2}$ absorption and desorption performance of the solvents were measured by a homemade apparatus as shown as Fig. 1 .

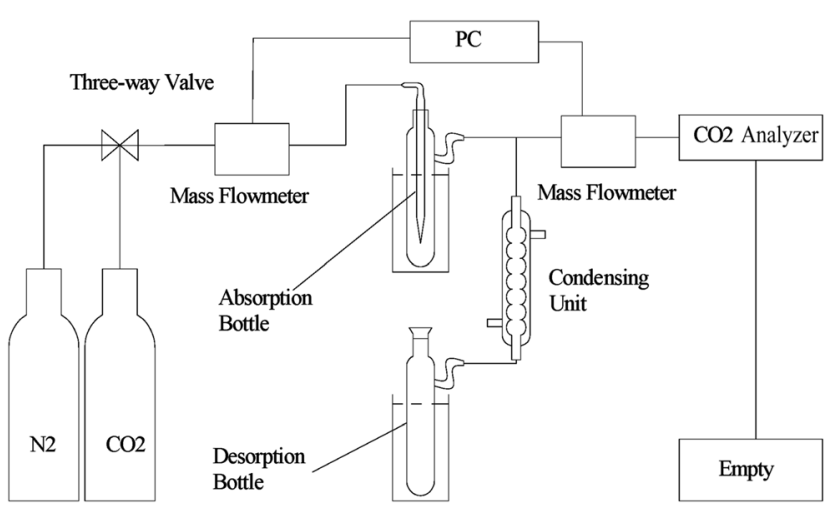

Fig. 1 Experimental apparatus for $\mathrm{CO}_{2}$ absorption/desorption.
The error between the measured $\mathrm{CO}_{2}$ solubility and the theoretical value is less than $5 \%$.

For $\mathrm{CO}_{2}$ absorption experiment, $\mathrm{CO}_{2}$ intake speed was controlled at approximately $60 \mathrm{~mL} \mathrm{~min}{ }^{-1}$ under 1 bar. $\mathrm{CO}_{2}$ intake and outlet flow was determined by mass flow meters (50L type, SIERRA Flow Measurement and Control Technology Company of USA) with measurement error range of $\pm 1 \%$, which was recorded by a computer every $30 \mathrm{~s}$. $\mathrm{CO}_{2}$ intake flow was recorded as $V_{i}$ and $V_{i}^{\prime}$ for $\mathrm{CO}_{2}$ outlet flow at time " $i$ ". The volume of $\mathrm{CO}_{2}$ solubility in the investigated solvents $\left(\Delta V_{i}, \mathrm{~mL}\right)$ could be obtained by eqn (1). $\mathrm{CO}_{2}$ absorption volume at time " $t$ " $\left(Q_{\mathrm{a}}, \mathrm{mL}\right)$ and the molar fraction of $\mathrm{CO}_{2}\left(X_{\mathrm{CO}_{2}}\right.$, unit: $\mathrm{mol} \mathrm{CO}_{2}$ per mol mixture, expressed as mol per $\mathrm{mol}$ ) in the solvents was calculated from eqn (2) and (3).

$$
\begin{aligned}
\Delta V_{i} & =V_{i}-V^{\prime}{ }_{i} \\
Q & =\sum_{i=0}^{t} \Delta V_{i} \\
X_{\mathrm{CO}_{2}} & =\frac{\frac{Q_{\mathrm{a}}}{22.4 \times 1000}}{n_{\mathrm{M}}+n_{\mathrm{I}}}
\end{aligned}
$$

where $n_{\mathrm{M}}$ and $n_{\mathrm{I}}$ was the molar amount of MEA and [ $\left.\mathrm{NH}_{2} \mathrm{e}-\mathrm{mim}\right]$ $\left[\mathrm{BF}_{4}\right]$ in the investigated absorbents.

During $\mathrm{CO}_{2}$ desorption, temperature was regulated to range from $383 \mathrm{~K}$ to $398 \mathrm{~K}$. $\mathrm{CO}_{2}$ liberation volume was measured by a mass flowmeter and recorded in a computer. $\mathrm{CO}_{2}$ desorption capacity $\left(Q_{\mathrm{d}}, \mathrm{mL}\right)$ was also calculated by eqn (2). And $\mathrm{CO}_{2}$ desorption efficiency $(\eta$, \%) was defined as the percentage of $\mathrm{CO}_{2}$ desorption capacity to corresponding $\mathrm{CO}_{2}$ absorption capacity, which could be calculated by eqn (4).

$$
\eta=\frac{Q_{\mathrm{d}}}{Q_{\mathrm{a}}} \times 100 \%
$$

The investigated solvents were subjected to the steps previously mentioned to carry out $\mathrm{CO}_{2}$ absorption-desorption cycle experiments.

\section{Results and discussion}

\section{Physical properties of the investigated solvents}

Density and viscosity of the investigated solvents at $303 \mathrm{~K}$ under 1 bar were shown in Fig. 2 .

The density value of the mixed absorbents was between the density value of $30 \mathrm{vol} \%$ solution $\left(1007.2 \mathrm{~kg} \mathrm{~m}^{-3}\right)$ and the $\left[\mathrm{NH}_{2} \mathrm{e}-\mathrm{mim}\right]\left[\mathrm{BF}_{4}\right]\left(1472.2 \mathrm{~kg} \mathrm{~m}^{-3}\right)$ which were measured at the same condition. And the viscosity of the mixed absorbents also showed the same law. The viscosity of $\left[\mathrm{NH}_{2} \mathrm{e}-\mathrm{mim}\right]\left[\mathrm{BF}_{4}\right]$ was $3589.2 \mathrm{mPa}$ s determined by our group, ${ }^{22,34}$ while the viscosity of the absorbents was below $10 \mathrm{mPa} s$ with $n_{\mathrm{I}}$ of $0-0.6$, which showed that the addition of 30 vol\% solution reduced the viscosity of absorbents significantly. According to Fig. 2, both the density and the viscosity of the investigated absorbents increased with the increase of $n_{\mathrm{I}}$. The density was basically linear related to $n_{\mathrm{I}}$ and the slope of viscosity kept increasing with the increase of $n_{\mathrm{I}}$ when $n_{\mathrm{I}}$ exceed 0.2 . 

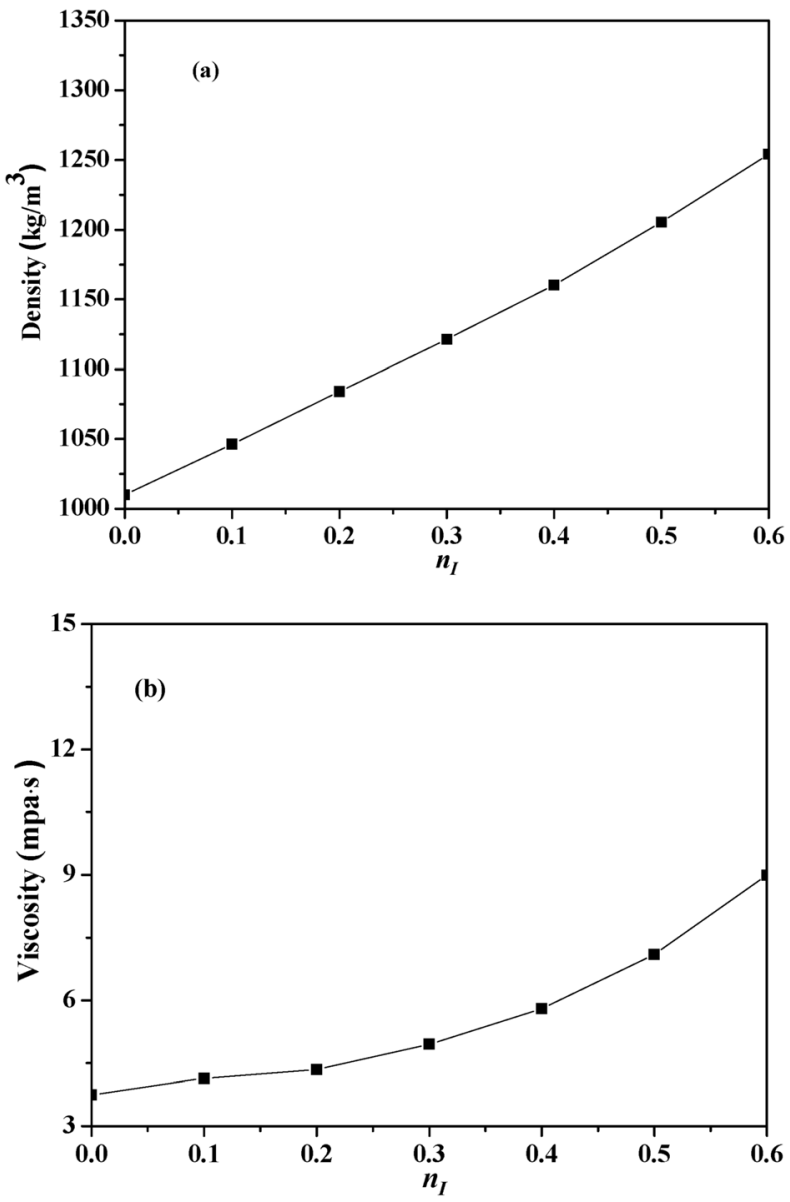

Fig. 2 Physical properties of the absorbents with different $n_{1}$ at $303 \mathrm{~K}$ : (a) density; (b) viscosity.

\section{Effects of the $n_{I}$ on the absorption performance}

Fig. 3 illustrated the effects of $n_{\mathrm{I}}$ on $\mathrm{CO}_{2}$ absorption performance at $303 \mathrm{~K}$ under 1 bar.

As shown in Fig. 3(a), with the increase of $n_{\mathrm{I}}, \mathrm{CO}_{2}$ absorption capacity increased initially, and reached a maximum of $0.4554 \mathrm{~mol}$ per mol (contrasting with a value of $0.4601 \mathrm{~mol} \mathrm{CO}_{2}$ per mol MEA measured at the same condition) when $n_{\mathrm{I}}$ was 0.2 , then decreased, which suggested there was an optimum $n_{\mathrm{I}}$ in the absorbent for $\mathrm{CO}_{2}$ absorption. In Fig. 3(b), as time went on, the absorption rate of all absorbents decreased rapidly within 12 minutes, and then decreased gently. With the increasing of $n_{\mathrm{I}}, \mathrm{CO}_{2}$ absorption rate increased firstly and then decreased, which suggested that an optimal $n_{\mathrm{I}}$ also existed.

$\mathrm{CO}_{2}$ absorption performance was influenced by the viscosity of the absorbents, the imidazole ring content and the amine group content in the absorbents. ${ }^{35,36} \mathrm{CO}_{2}$ absorption capacity was defined as the amount of $\mathrm{CO}_{2}$ absorption per mol amine in this work, thus the variation of $\mathrm{CO}_{2}$ absorption performance was mainly caused by the viscosity and the imidazole ring content of the absorbents. On the one hand, $\left[\mathrm{NH}_{2} \mathrm{e}-\mathrm{mim}\right]\left[\mathrm{BF}_{4}\right]$ concentration increased as $n_{\mathrm{I}}$ increased and consequently increased the viscosity of the absorbents just as Fig. 2(b) shown, which militated against the contact of $\mathrm{CO}_{2}$ and the absorbents.
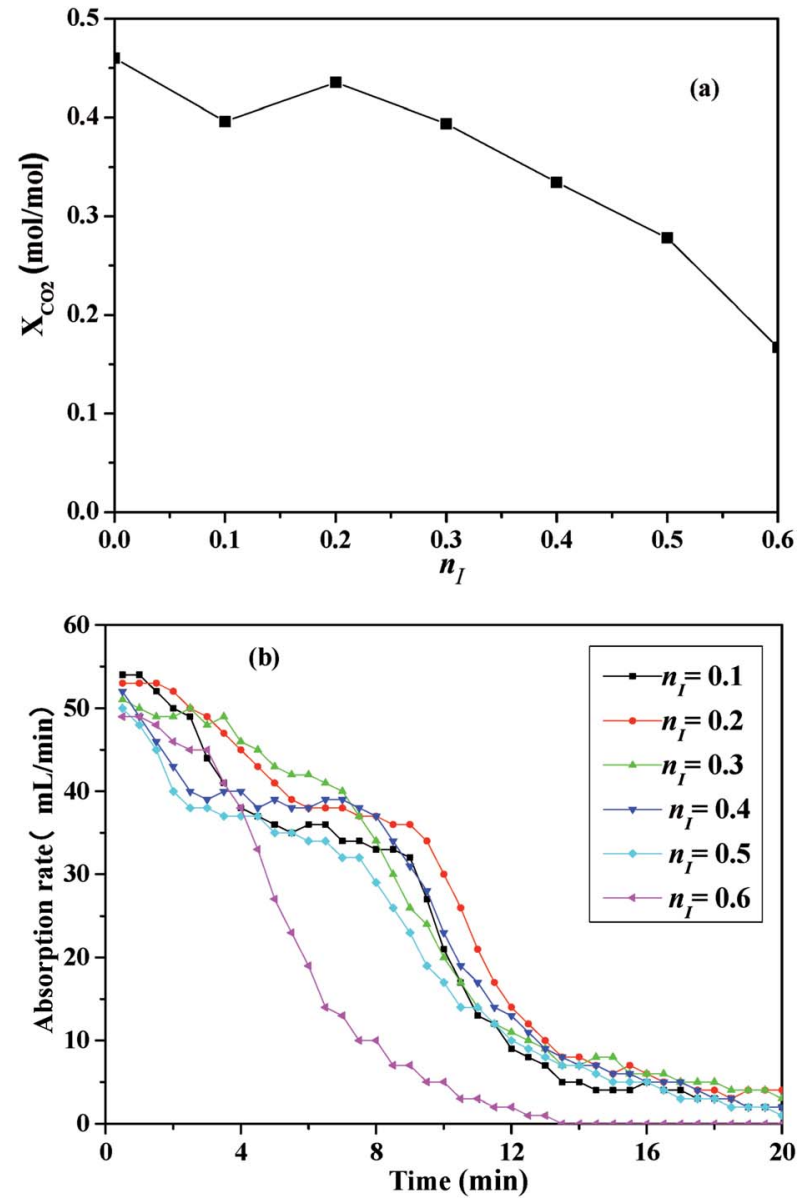

Fig. $3 \mathrm{CO}_{2}$ absorption performance of the absorbents with different $n_{1}$ at $303 \mathrm{~K}$ : (a) the absorption capacity; (b) the absorption rate.

On the other hand, the increase of $n_{\mathrm{I}}$ should cause the increase of the imidazole ring content in the absorbent, which benefits $\mathrm{CO}_{2}$ absorption. ${ }^{36}$ The comprehensive effects of the factors caused that $\mathrm{CO}_{2}$ absorption performance increased and then decreased with the increase of $n_{\mathrm{I}}$.

As illustrated in Fig. 3, the absorbent prepared with $n_{\mathrm{I}}$ of 0.2 $\left(\mathrm{I} / \mathrm{M}_{2: 8}\right)$ showed the best absorption performance. Thus, a comparison between the absorption rate of the $\mathbf{I} / \mathbf{M}_{2: 8}$ and the MEA solution at $303 \mathrm{~K}$ under 1 bar had been made in Fig. 4 . At the early stage (0-10 minutes), the aqueous MEA solution showed higher absorption rate than the mixture of $\left[\mathrm{NH}_{2} \mathrm{e}-\mathrm{mim}\right]$ $\left[\mathrm{BF}_{4}\right]$ and MEA. After ten minutes, the mixture absorbent showed a higher absorption rate, which suggested that an moderate amount of $\left[\mathrm{NH}_{2} \mathrm{e}-\mathrm{mim}\right]\left[\mathrm{BF}_{4}\right]$ would contribute to increasing $\mathrm{CO}_{2}$ absorption rate at the later stage mainly.

Considering that the mixed absorbent with the $\mathrm{I} / \mathbf{M}_{2: 8}$ showed the best absorption performance, the mixed absorbent mentioned below was prepared with this ratio.

\section{Effects of the temperature on the absorption performance}

Fig. 5 showed the effects of the temperature on $\mathrm{CO}_{2}$ absorption capacity and rate of the $30 \mathrm{vol} \%$ MEA solution and the $\mathrm{I} / \mathbf{M}_{2: 8}$. According to Fig. 5(a), the $\mathrm{CO}_{2}$ absorption capacity decreased as 


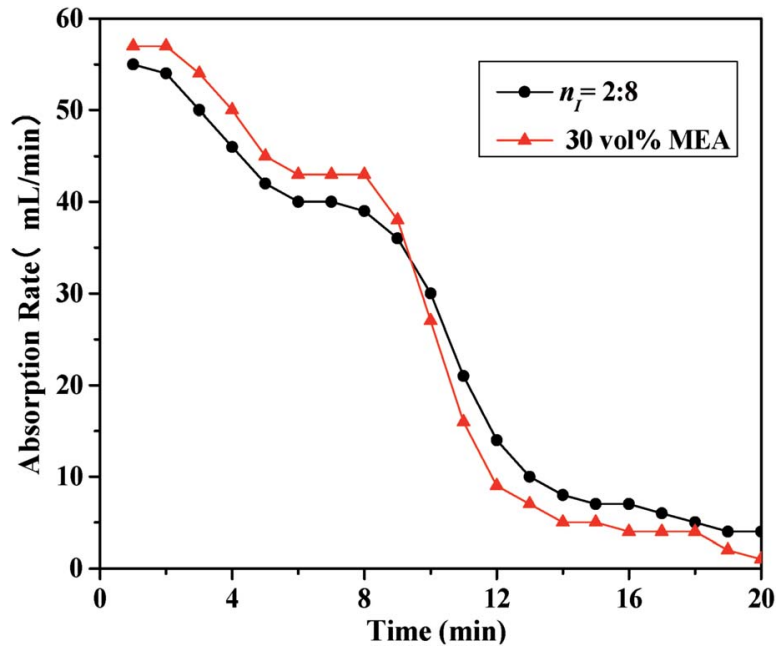

Fig. 4 Comparison of $\mathrm{CO}_{2}$ absorption rate between the absorbent with $n_{1}$ of 0.2 and the 30 vol\% MEA solution at $303 \mathrm{~K}$.

the temperature increased. The comparison between the $\mathrm{CO}_{2}$ absorption capacity of the mixed absorbent and the MEA solution illustrated that $\mathrm{CO}_{2}$ absorption capacity of the latter was comparable to the former. From Fig. 5(b), the $\mathrm{CO}_{2}$ absorption
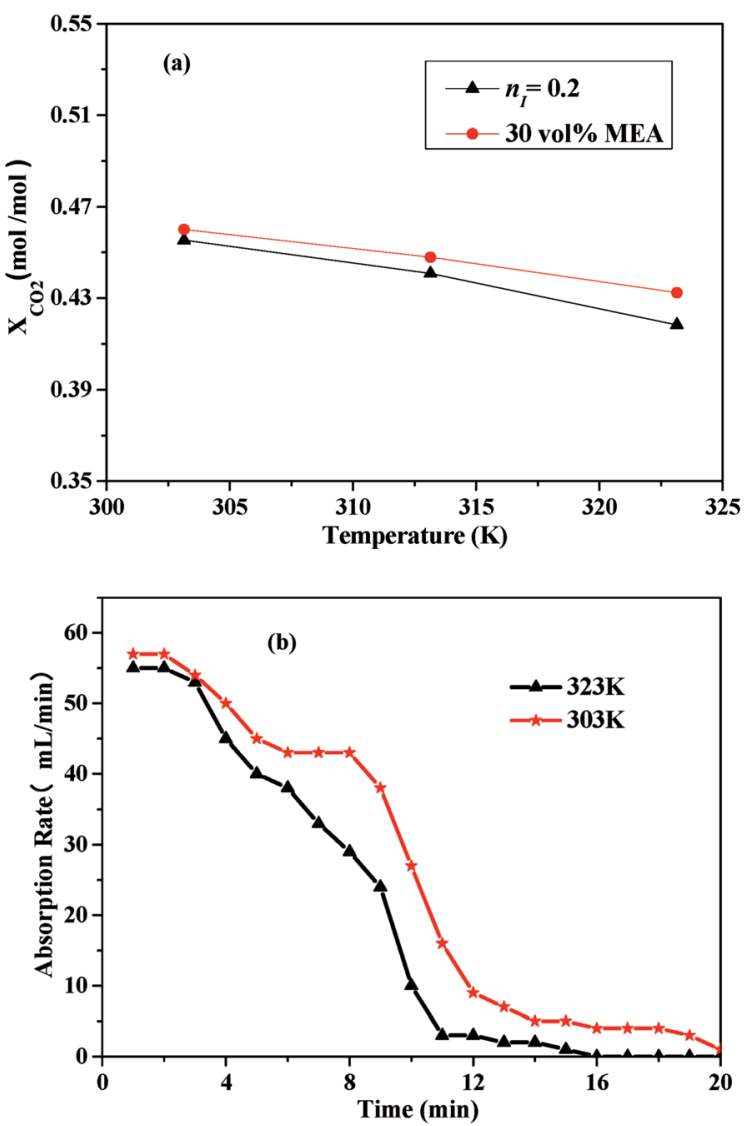

Fig. $5 \mathrm{CO}_{2}$ absorption performance of the I/M $\mathrm{M}_{2: 8}$ absorbent: (a) $\mathrm{CO}_{2}$ absorption capacity vs. temperature; (b) $\mathrm{CO}_{2}$ absorption rate vs. time at $303 \mathrm{~K}$ and $323 \mathrm{~K}$. rate decreased with the temperature ranged from $303 \mathrm{~K}$ to 323 $\mathrm{K}$. Absorption equilibrium could be reached a little bit earlier at a higher temperature of $323 \mathrm{~K}$, which might due to a lower $\mathrm{CO}_{2}$ absorption capacity.

Therefore, both $\mathrm{CO}_{2}$ absorption capacity and $\mathrm{CO}_{2}$ absorption rate of the absorbents decreased with increasing of temperature. Similar result could be found in the previous studies. ${ }^{37-39}$

\section{Effects of the temperature on the desorption performance}

Fig. 6 presented the desorption performance of the $\mathrm{I} / \mathrm{M}_{2: 8}$ at different temperature and the desorption performance of 30 vol\% MEA at $383 \mathrm{~K}$ under 1 bar. As shown in Fig. 6(a), all the desorption efficiency increased significantly at the beginning (0-40 minutes) and then increased gently until desorption equilibrated. With the increasing of temperature, the desorption efficiency increased. The desorption efficiency of the $\mathbf{I} / \mathbf{M}_{2: 8}$ was much higher than that of the aqueous MEA at the same temperature and it exceeded $50 \%$ in 30 minutes. By contrast, the MEA solution needed an hour to reach the desorption efficiency of $50 \%$. The desorption rate decreased intensively first and then decreased slightly until desorption balanced, as shown in Fig. 6(b). With increasing temperature, the desorption rate increased, which followed the same trend as the desorption efficiency. As it could be seen in Fig. 6, the desorption efficiency and the desorption rate at $393 \mathrm{~K}$ were close to the values at 398
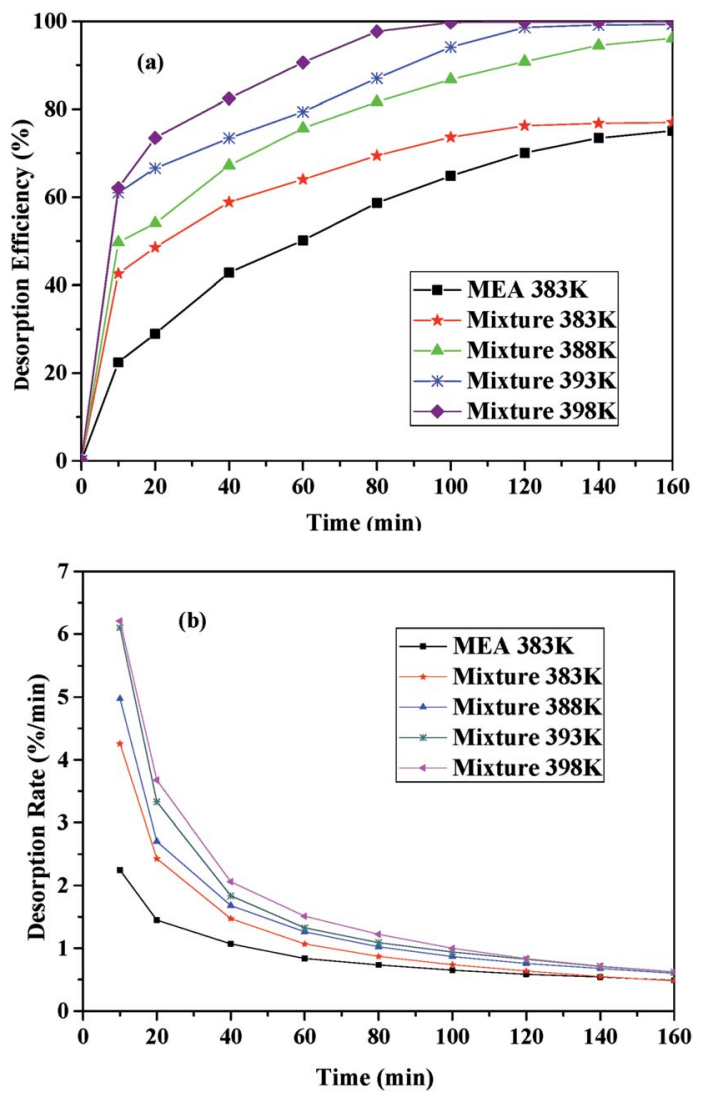

Fig. $6 \mathrm{CO}_{2}$ desorption performance the $1 / \mathrm{M}_{2: 8}$ absorbent at different temperature: (a) the desorption efficiency vs. time; (b) the desorption rate vs. time. 
$\mathrm{K}$. Considering the energy-consumption, $393 \mathrm{~K}$ was chosen as the optimum desorption temperature of the mixture with $\mathrm{CO}_{2}$ desorption efficiency of $99.31 \%$, which was lower than that of the $30 \mathrm{vol} \%$ MEA solution (398 K).

According to Fig. 6, $\mathrm{CO}_{2}$ desorption efficiency and rate of the I/ $\mathbf{M}_{2: 8}$ were higher than that of the aqueous MEA at the same conditions, which suggested that the mixture absorbents had a lower energy consumption for regenerations compared with the aqueous alcohol. The energy-consumption of $\mathrm{CO}_{2}$ desorption involved three parts: the energy for the increase of the mixture temperature, which was the product of the mole quantity, molar heat capacity and the differential of the temperature; the energy for the escape of $\mathrm{CO}_{2}$, which was equal to the absorption heat of $\mathrm{CO}_{2}$; and the energy for the vaporization of the absorbent. ${ }^{1}$ The regeneration temperature of the functional ILs was from $263 \mathrm{~K}$ to $343 \mathrm{~K},{ }^{40}$ which was lower than that of the alcohol amine. Thus, the ILs needed less energy for the increase of the temperature. The absorption heat depended on the heat of the reaction between the absorbents and $\mathrm{CO}_{2}$, which were nearly the same for these two absorbents. Therefore, the energy for the escape of $\mathrm{CO}_{2}$ from the two absorbents showed little change. The regeneration temperature of the MEA solution was higher than ILs, accordingly, the vaporization of water and MEA needed more energy. Consequently, $\mathrm{CO}_{2}$ desorption of ILs system required less energy than the MEA system, which suggested that the ILs was an economical solution for $\mathrm{CO}_{2}$ capture.

\section{Stability performance of the absorbent}

To examine the stability performance of the absorbents, properties including $\mathrm{CO}_{2}$ adsorption capacity, mass loss, density and viscosity of the MEA solution and the $\mathrm{I} / \mathbf{M}_{2: 8}$ were circularly tested for 5 times. The absorption temperature was $303 \mathrm{~K}$, and the time of duration was $30 \mathrm{~min}$. The desorption temperature of MEA solution was $398 \mathrm{~K}$, while the desorption temperature of I/ $\mathbf{M}_{2: 8}$ was $393 \mathrm{~K}$, and the time of duration was $120 \mathrm{~min}$. Fig. 7 showed the properties of the absorbents in each cycle.

As shown in Fig. 7(a), the values of $\mathrm{CO}_{2}$ absorption capacity of the MEA solution and the $\mathbf{I} / \mathbf{M}_{2: 8}$ decreased gradually in five absorption-desorption cycles. And the decrease percentage of $\mathrm{CO}_{2}$ absorption capacity of the $\mathrm{I} / \mathrm{M}_{2: 8}$ were slightly less than those of MEA. However, the mass weight loss of the two absorbents in the 5 cycles showed different trends. The weight loss percentage of the $\mathrm{I} / \mathbf{M}_{2: 8}$ was $3 \%$ relative to the first circle after one cycle, and then the weight was a small loss during the next four cycles. By contrast, the mass of MEA system decreased more obviously, and the percent of the decline values increased as the number of the circles went up. The difference of the two absorbents might be caused by the water and MEA which was more volatile at a higher temperature of $393 \mathrm{~K}$. To verify the reason of the phenomenon, the density and the viscosity of the absorbents were measured respectively in each circle. The results were shown in Fig. 7(b).

As illustrated in Fig. 7(b), as the number of absorptiondesorption cycles went up, the density of the absorbents increased gently and then became invariant after the third cycle. In the second cycle, the density of the $\mathbf{I} / \mathbf{M}_{2: 8}$ increased about
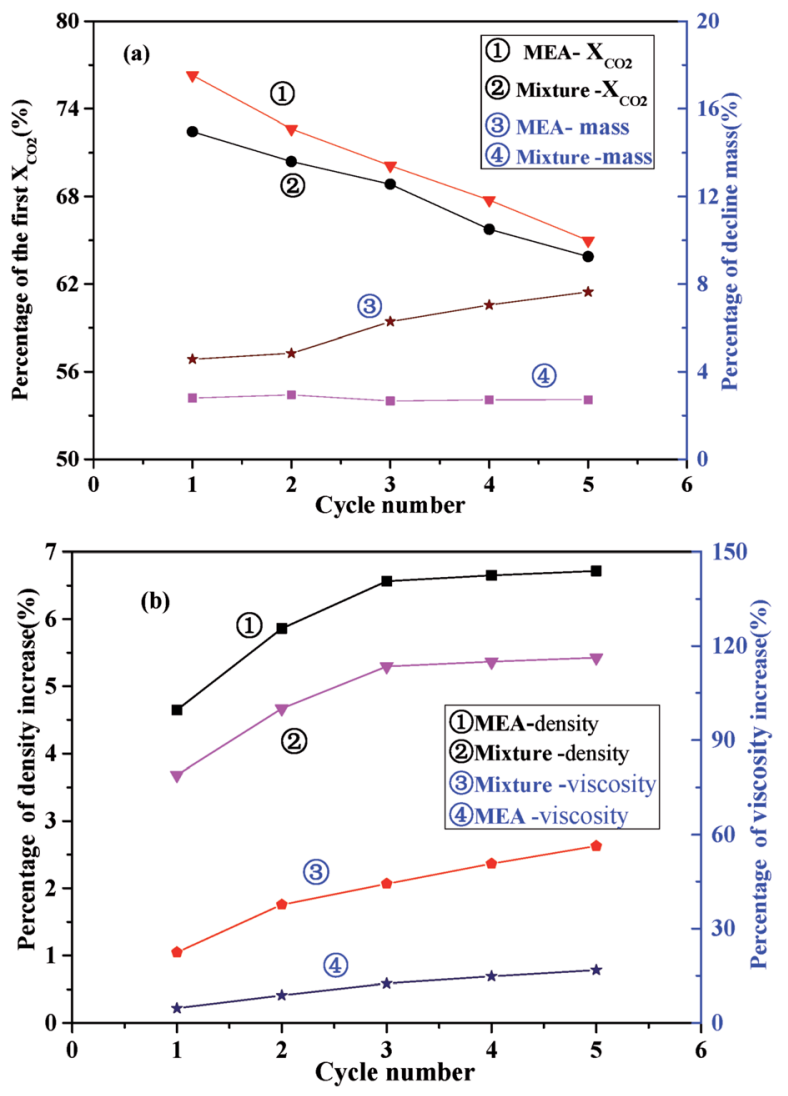

Fig. 7 Properties of the $1 / M_{2: 8}$ absorbent during 5 times cycle: (a) $\mathrm{CO}_{2}$ adsorption capacity as a percentage of the first time and percentage of quality decline compared with the first time; (b) percentage of density and viscosity increase compared with the first time.

$3.5 \%$ relative to the first circle, while the increase amount of the MEA solution was about $4.5 \%$. The viscosity of the absorbents also increased as the number of absorption-desorption cycles went up. The viscosity of the MEA solution increased in a range of $2-5 \%$ with the increase of the cyclic times. And for the $\mathrm{I} / \mathrm{M}_{2: 8}$, it increased about $12 \%$ relative to the first circle, and the growth rate slowed down after the second circle with the increase amount of about $5 \%$. The viscosity value of the mixture was in a range of $4-10 \mathrm{mPa} s$ at $303 \mathrm{~K}$, which was still a moderate viscosity for $\mathrm{CO}_{2}$ adsorption. From the above results, it suggested that the mixture of ILs and MEA showed a better stability of density and a larger change of viscosity, which mitigated the loss of volatile MEA and water in the absorbents.

According to Fig. 7, it was concluded that the mixture of IL and MEA had a better stability in $\mathrm{CO}_{2}$ adsorption capacity, mass loss and density and had a better thermodynamic stability than the MEA solution.

\section{Conclusions}

In this work, absorbents with excellent $\mathrm{CO}_{2}$ capture performance were developed by mixing $30 \mathrm{vol} \%$ MEA solution with an ionic liquid $\left[\mathrm{NH}_{2} \mathrm{e}-\mathrm{mim}\right]\left[\mathrm{BF}_{4}\right]$. The density and the viscosity of the absorbents increased with the increase of $n_{\mathrm{I}}$. The addition of 
MEA solution reduced the viscosity of absorbents to no more than $10 \mathrm{mPa}$.

The absorbent exhibited a rather excellent $\mathrm{CO}_{2}$ capture performance when $n_{\mathrm{I}}$ was 0.2: (1) a moderate $\left[\mathrm{NH}_{2} \mathrm{e}-\mathrm{mim}\right]\left[\mathrm{BF}_{4}\right]$ could contribute to increasing $\mathrm{CO}_{2}$ absorption rate at the later stage; (2) $\mathrm{CO}_{2}$ absorption capacity of the $\mathrm{I} / \mathrm{M}_{2: 8}$ could comparable with the $30 \mathrm{vol} \%$ MEA solution. It contributed to advance the $\mathrm{CO}_{2}$ absorption process to increase temperature, however, $\mathrm{CO}_{2}$ absorption capacity and rate decreased.

Both $\mathrm{CO}_{2}$ desorption efficiency and $\mathrm{CO}_{2}$ desorption rate increased with increasing temperature. And $\mathrm{CO}_{2}$ desorption efficiency and rate was higher than the $30 \mathrm{vol} \%$ solution at the same conditions. Considering the energy-consumption, $393 \mathrm{~K}$ was chosen as the optimum desorption temperature, which was $5 \mathrm{~K}$ lower than the MEA solution.

Compared with MEA solution, the absorbent of $\mathbf{I} / \mathbf{M}_{2: 8}$ showed a better cyclic stability. The reason was that the addition of $\left[\mathrm{NH}_{2} \mathrm{e}-\mathrm{mim}\right]\left[\mathrm{BF}_{4}\right]$ into the MEA could improve the thermodynamic stability of the absorbent.

\section{Conflicts of interest}

There are no conflicts to declare.

\section{Acknowledgements}

The authors are grateful for Hubei Province Excellent Science and Technology Innovation Team Project (T201407).

\section{References}

1 C. Wang, X. Luo, X. Zhu, G. Cui, D. Jiang, D. Deng, H. Li and S. Dai, RSC Adv., 2013, 3, 15518-15527.

2 Indian People Organizing for Change, Environmental Policy Collection, 2014, vol. 27, p. 408.

3 D. S. Jenkinson, D. E. Adams and A. Wild, Nature, 1991, 351, 304-306.

4 M. Zhao, A. I. Minett and A. T. Harris, Energy Environ. Sci., 2012, 6, 25-40.

5 A. E. Creamer and B. Gao, Environ. Sci. Technol., 2016, 50, 7276.

6 F. Johnsson, Greenhouse Gases: Sci. Technol., 2011, 1, 119133.

7 K. S. Lackner, Science, 2015, 300, 1677-1678.

8 L. J. Hyun, K. Jun-Han, L. I. Young, J. K. Ryoung and S. JaeGoo, J. Chem. Eng. Jpn., 2010, 43, 720-726.

9 S. Kenarsari, D. Yang, G. Jiang, S. Zhang, J. Wang, A. Russell, Q. Wei and M. Fan, RSC Adv., 2013, 3, 22739-22773.

10 N. Harun and P. L. Douglas, Int. J. Greenhouse Gas Control, 2012, 10, 295-309.

11 P. Mores, N. Scenna and S. Mussati, Energy, 2012, 45, 10421058.

12 L. Faramarzi, G. M. Kontogeorgis, M. L. Michelsen, K. Thomsen and E. H. Stenby, Ind. Eng. Chem. Res., 2010, 49, 3751-3759.

13 M. Gupta, E. F. D. Silva, A. Hartono and H. F. Svendsen, J. Phys. Chem. B, 2013, 117, 9457-9468.
14 X. Zhang, X. Zhang, H. Dong, Z. Zhao, S. Zhang and Y. Huang, Energy Environ. Sci., 2012, 5, 6668-6681.

15 G. Wang, W. Hou, X. Feng, G. Jiao, Y. Wu and Z. Zhang, J. Chem. Eng. Data, 2011, 56, 1125-1133.

16 X. M. Zhang, K. Huang, S. Xia, Y. L. Chen, Y. T. Wu and X. B. Hu, Chem. Eng. J., 2015, 274, 30-38.

17 J. Q. Wang, W. G. Cheng, J. Sun, T. Y. Shi, X. P. Zhang and S. J. Zhang, RSC Adv., 2013, 4, 2360-2367.

18 Z. Z. Yang, Y. N. Zhao and L. N. He, RSC Adv., 2011, 1, 545-567. 19 T. Y. Shi, J. Q. Wang, J. Sun, M. H. Wang, W. G. Cheng and S. J. Zhang, RSC Adv., 2013, 3, 3726-3732.

20 L. M. G. Sánchez, G. W. Meindersma and A. B. D. Haan, Chem. Eng. J., 2011, 166, 1104-1115.

21 M. Gonzalezmiquel, J. Bedia, C. Abrusci, J. Palomar and F. Rodriguez, J. Phys. Chem. B, 2013, 117, 3398-3406.

22 M. Wang, L. Zhang, L. Gao, K. Pi, J. Zhang and C. Zheng, Energy Fuels, 2013, 27, 461-466.

23 E. D. Bates, R. D. Mayton, A. Ioanna Ntai and J. H. Davis Jr, J. Am. Chem. Soc., 2002, 124, 926.

24 R. Vijayraghavan, S. J. Pas, E. I. Izgorodina and D. R. Macfarlane, Phys. Chem. Chem. Phys., 2013, 15, 19994.

25 B. F. Goodrich, D. L. F. Jc, B. E. Gurkan, Z. K. Lopez, E. A. Price, Y. Huang and J. F. Brennecke, J. Phys. Chem. B, 2011, 115, 9140-9150.

26 Y. S. Sistla and A. Khanna, J. Ind. Eng. Chem., 2014, 20, 24972509.

27 Z. Zhou, X. Zhou, G. Jing and B. Lv, Energy Fuels, 2016, 30, 7489-7495.

28 M. S. Shannon and J. E. Bara, Sep. Sci. Technol., 2012, 47, 178-188.

29 Y. Shim and H. J. Kim, J. Phys. Chem. B, 2010, 114, 10160-10170.

30 S. Zeng, J. Wang, L. Bai, B. Wang, H. Gao, D. Shang, X. Zhang and S. Zhang, Energy Fuels, 2015, 29, 6039-6048.

31 J. J. Chen, W. W. Li, X. L. Li and H. Q. Yu, Phys. Chem. Chem. Phys., 2012, 14, 4589-4596.

32 S. A. Prikhod'Ko, A. Y. Shabalin, V. V. Bardin, I. V. Eltsov, I. K. Shundrina, V. N. Parmon and N. Y. Adonin, RSC Adv., 2017, 7, 17497-17504.

33 M. Wang, L. Q. Zhang, H. Liu, J. Y. Zhang and C. G. Zheng, J. Fuel Chem. Technol., 2012, 40, 1264-1268.

34 M. Wang, L. Q. Zhang, M. Yang and W. Y. Hu, J. Wuhan Polytech. Univ., 2014, 41-45.

35 X. Lei, Y. Xu, L. Zhu and X. Wang, RSC Adv., 2014, 4, 7052-7057. 36 A. H. Jalili, A. Mehdizadeh, M. Shokouhi, H. Sakhaeinia and V. Taghikhani, Fluid Phase Equilib., 2010, 42, 787-791.

37 M. P. Gimeno, M. C. Mayoral and J. M. Andrés, Energy Fuels, 2013, 27, 3928-3935.

38 S. Ren, Y. Hou, W. Wu, S. Tian and W. Liu, RSC Adv., 2012, 2, 2504-2507.

39 Y. Yasaka and Y. Kimura, J. Chem. Eng. Data, 2016, 61, 837845.

40 B. F. Goodrich, J. C. D. L. Fuente, B. E. Gurkan, D. J. Zadigian, E. A. Price, Y. Huang and J. F. Brennecke, Ind. Eng. Chem. Res., 2011, 50, 111-118. 